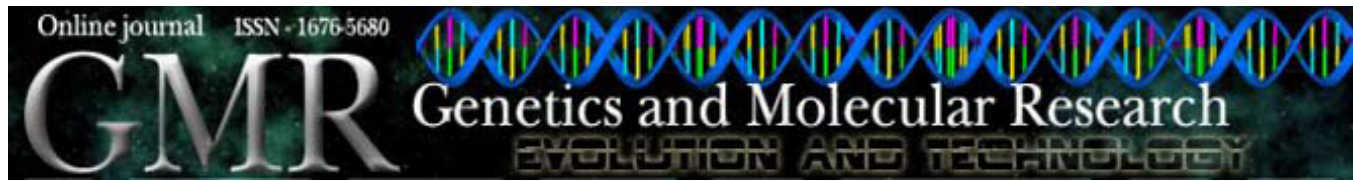

\title{
Evaluation of cancer records from 2000-2004 in Denizli, Turkey
}

\author{
A. Köksal ${ }^{1}$, H.Ç. Sorkun ${ }^{1}$, H. Demirhan ${ }^{1}$, A.G. Tomatır², T. Alan ${ }^{3}$ \\ and F. Özerdem ${ }^{3}$ \\ ${ }^{1}$ Health Services Vocational School, Pamukkale University, Denizli, Turkey \\ ${ }^{2}$ Department of Medical Biology, Pamukkale University Medical Faculty, \\ Denizli, Turkey \\ ${ }^{3}$ Turkish Ministry of Health, Denizli, Turkey \\ Corresponding author: A.G. Tomatır \\ E-mail: tomatir@pau.edu.tr / aysegaye@hotmail.com
}

Genet. Mol. Res. 8 (1): 64-75 (2009)

Received October 13, 2008

Accepted November 18, 2008

Published January 27, 2009

\begin{abstract}
Objective information about cancer incidence is important for planning control programs. We examined the distribution of cancer cases recorded in Denizli province, Turkey. A total of 2185 cancer cases reported to the Denizli Province Health Ministry's Cancer Early Diagnosis Center during the years 2000-2004 were evaluated for sociodemographic characteristics, cigarette use, family history, and organ systems. Among these cases, $56 \%$ were male and $44 \%$ were female; $45.1 \%$ of the patients had smoked cigarettes at some time and there was a 10 -fold increase in lung cancer and a 4-fold increase in urinary cancers among cigarette smokers $(\mathrm{P}<0.001)$. We found that $34.4 \%$ of the cancer cases were diagnosed as localized, $27.9 \%$ had a more extensive distribution and $21.8 \%$ were in metastasis. The most frequent types were urinary cancers at $26.4 \%$, gastrointestinal cancers at $19.2 \%$ and respiratory cancers at $18.9 \%$; there was a significant increase in gastrointestinal, blood and skin cancers over the years. Lung $(14.9 \%)$, breast $(14.1 \%)$, bladder $(8.0 \%)$, prostate $(5.3 \%)$, and lymphatic $(4.8 \%)$ cancer cases were the most common.
\end{abstract}

Key words: Cancer records; Cancer incidence; Retrospective study; Turkey 


\section{INTRODUCTION}

The population of Turkey in the year 2007 census was determined to be 70.5 million people (http://tuikrapor.tuik.gov.tr/reports/rwservlet?adnks=\&report=turkiye_yasgr.RDF\&desf ormat $=\mathrm{html} \& E N V I D=a d n k s E n v)$. The site of this study, Denizli, is located in the interior section of Turkey's Aegean region. Denizli province is in western Turkey; apart from the city of Denizli, it is made up of 18 towns and 372 villages. According to address based on 2007 census, the provincial capital have a total population of 323,151 , while the villages have a total population of 171,810 , making a total population for the area of 907,325 people, of whom 453,756 are men and 453,569 are women (http://www.denizli.gov.tr/denizli/genelbilgiler.htm\#NÜFUS).

In spite of several attempts, real cancer incidence data have never been available for a defined population within Turkey. The Ministry of Health established a "passive cancer registration system" for the entire country in 1983, but information could only be obtained for approximately one-quarter of the estimated total of cancer cases. Thus, the Ministry of Health, together with the Turkish Association of Cancer Control, initiated a new "active data collection system" in ten provinces in 1992. The first results from this system, for the years 1993-1994, have been published (Turkish Ministry of Health, Department of Cancer Control, 1997).

Cancer is a serious health problem where it is the second leading cause of death following cardiovascular diseases in the world and in our country. Statistics on cancer in Turkey have been published from time to time (http://www.saglik.gov.tr/TR/BelgeGoster.aspx? F6E10F8892433CFF71BE64510F6C8BC92747D9FFFE7A126). According to the Ministry of Health, based on 1994 data, the incidence of cancer was 33.1 per 100,000 for adults in the general population, but this rate was found to be 103 per 100,000 in Antalya, which was chosen as a pilot region. The incidence for the 25,942 cases reported in 1999 in our country was determined to be 39.4 per 100,000 (Turkish Ministry of Health, 1997). In addition, in a study conducted in İzmir between 1993-1994 by Fidaner et al. (2001), the incidence standardized for age was found to be 157.5 per 100,000 in men and 94 per 100,000 in women. In addition to cancer having an important place among chronic illnesses, it is also an illness with psychosocial and economic sides for the family and the country. In the year 2002 around the world, and regarding the 26 types of reported cancers, there were 10.9 million new cases of cancer, 6.7 million people died from cancer and 24.6 million people were found to be living with cancer (http://www.gata.edu.tr/dahilibilimler/onkoloji/kanser_epidemiyolojisi. $\mathrm{htm}$ ). There were 8.1 million new cases of cancer reported in the year 1990, and thus it is noteworthy that within 12 years, there was an increase in newly diagnosed cases of cancer of approximately 30\% (http://www.turkkanser.org.tr/newsfiles/61dunya_kanser_istatistikleri. pdf). Currently, there are 10 million new cases per year that occur throughout the world, and of these, 5.3 million (53\%) are men and 4.7 million (47\%) are women (Eaton, 2003). Since 2000, there have been 6 million cancer-related deaths in the world in general, and 1.6 million of these deaths occurred in Europe (Parkin, 2001; Bray et al., 2003). In the year 2000 , there were 22 million cancer patients living in the world, and the first five types of cancer were lung, breast, colorectal, stomach, and liver cancers (Parkin, 2001). In the world in general, the cancer-related death rate is higher in developed countries than in developing countries. However, the cancer-related morbidity and mortality rates are higher in developing countries (Parkin et al., 1999). In our country, 10.1\% of all deaths were cancer-related in 1990, but this percentage reached $12.4 \%$ in 1999, taking second place behind deaths from 
cardiac diseases (Turkish Republic Ministry of State Statistics Institute Publications, 2002). In the US, $23 \%$ of all deaths were cancer-related in 2001, also in second place (Jemal et al., 2004). Estimates of incidence have been prepared for 5 broad age groups: 0-14, 15-44, 4554, 55-64, and 65 years and older. Age-standardized incidence rates were calculated using the weights of the "world standard" population $(0.31,0.43,0.11,0.08$, and 0.07 in these 5 age classes) (Parkin et al., 1999). Although the percentages of cancer and death vary among countries, the cancer incidence, etiologic factors and most frequent types of cancer should be known (http://www.gata.edu.tr/dahilibilimler/onkoloji/kanser_epidemiyolojisi.htm, http:// www.turkkanser.org.tr/newsfiles/61dunya_kanser_istatistikleri.pdf; WHO, 2003; Süzek et al., 2004). In the determination of the incidence of cancer in a society, it is necessary to examine hospital case records, mortality records, hospital discharge records, cancer screening programs, hospital statistics, laboratory records, autopsy records, and reporting centers (Sørensen et al., 2005).

Our purpose in this study was to present the relationship between distribution of cancer by year and organ system in general records for a 5-year period in a province with gender, age, place of birth, educational status, occupation, cigarette smoking habit, and family history, and to participate in the determination of approaches to cancer screening, diagnosis and treatment.

\section{MATERIAL AND METHODS}

This study relied on the Denizli Cancer Early Diagnosis Center (DCEDC), which collects data on all new cases of cancer from all hospitals $(\mathrm{N}=6)$ in the city, including university hospitals, state hospitals, hospitals of the social security administration, and private hospitals. Hospitals have hospital-based cancer registries, from which DCEDC receives the data directly, from the medical records onto specially designed notification forms. In addition, all reports from hospitals and primary health care centers in all towns in Denizli province are recorded.

The "Cervical Cancer Screening Center", founded by the Denizli Ministry of Health in 1996, was later changed to become the "Cancer Early Diagnosis Center". First, the keeping of cancer records, which had been the task of the Ministry of Health Statistics Department, was transferred to the Early Diagnosis Center in 2001. With this passive registration system at the Early Diagnosis Center, all cancer records kept by all health care facilities in Denizli province capital and towns were collected on a monthly basis. Since October 2005, cancer records have also been monitored by the Ministry of Health Cancer Registration office.

This population-based, descriptive study of cancer record was planned in close cooperation with the Turkish Ministry of Health. Permission and cooperation of the Denizli Province Health Minister and Ethics Committee approval were also obtained for this study.

The cancer case records reported to the Denizli Province Health Ministry's Cancer Early Diagnosis Center in the last five years (2000-2004) were examined retrospectively according to organ system. Data were obtained using a standardized format and diagnoses classified according to the International Statistical Classification of Diseases (10th revision) coding (WHO, 1992).

The gender, age, place of birth, educational status, occupation, family history, cigarette smoking habit, and current approaches to cancer diagnosis and treatment were examined. Although we classified cancers according to organ systems, in this study we also evaluated frequently occurring organ cancers, for example, lung, breast, bladder, prostate, and lymphatic cancers. 
Age groups were examined in 5-year periods, some data were grouped by calculating incidence, mean and percentage, and tables and figures were prepared.

The data obtained were analyzed statistically using the chi-square test, analysis of variance and independent $t$-test. Advanced chi-square analysis was also used to determine the relationship between cigarette smoking and lung cancer by gender.

\section{RESULTS}

The population distribution of Denizli province of 418,622 men and 415,674 women according to age and gender for the years 2000-2004 is shown in Table 1. When the sociodemographic characteristics for the total 2185 cancer cases were examined, it was seen that $56.0 \%$ of the cases were male and their mean age was $60.67 \pm 14.9$ years, and $44.0 \%$ were female with a mean age of $55.09 \pm 15.8$ years (Table 2). In the distribution of cancer cases, it was seen that $48.9 \%$ came from towns in the province. The educational status for $60 \%$ of the cancer cases was primary education; the first three occupational statuses were unemployed (39.5\%), agriculture-related workers $(23.0 \%)$ and retired $(11.7 \%)$, and the majority did not have a family history of cancer $(73.8 \%)$. In the distribution of types of cancer in the province's towns, it was seen that the first three were cancers of the reproductive, respiratory and gastrointestinal systems. In the detailed analysis, it was interesting to note that for those who are heavy laborers the top three cancer types were respiratory $(34.8 \%)$, gastrointestinal $(21.7 \%)$ and skin $(17.4 \%)$. Those with a family history had higher percentages of reproductive, respiratory, gastrointestinal, and skin cancers, but this increase was not statistically significant $(\mathrm{P}>0.05)$. The number of smokers for more than 10 years was very high and more than half $(56.0 \%)$ smoke as much as one pack a day; approximately one-fourth of the cancer cases who had quit smoking had done so two to five years previously.

Table 1. Population distribution of Denizli province according to age and gender for the years 2000-2004.

\begin{tabular}{lrrr}
\hline Age group (years) & Male & Female & Total \\
\hline $0-4$ & 35,351 & 33,711 & 69,062 \\
$5-9$ & 34,887 & 33,140 & 68,027 \\
$10-14$ & 34,592 & 33,413 & 68,005 \\
$15-19$ & 38,839 & 36,742 & 75,581 \\
$20-24$ & 39,692 & 38,925 & 78,617 \\
$25-29$ & 37,685 & 35,905 & 73,590 \\
$30-34$ & 33,824 & 32,881 & 66,705 \\
$35-39$ & 32,885 & 32,014 & 64,899 \\
$40-44$ & 29,008 & 28,021 & 57,029 \\
$45-49$ & 25,336 & 23,475 & 48,811 \\
$50-54$ & 20,178 & 20,864 & 41,042 \\
$55-59$ & 15,094 & 16,567 & 31,661 \\
$60-64$ & 12,982 & 14,609 & 27,591 \\
$65-69$ & 11,612 & 13,706 & 25,318 \\
$70-74$ & 8,895 & 10,981 & 19,876 \\
$75-79$ & 4,642 & 5,939 & 10,581 \\
$80-84$ & 1,889 & 2,777 & 4,666 \\
$85+$ & 1,231 & 2,004 & 3,235 \\
Total & 418,622 & 415,674 & 834,296 \\
\hline
\end{tabular}




\begin{tabular}{|c|c|c|}
\hline Characteristic & $\mathrm{N}$ & $\%$ \\
\hline \multicolumn{3}{|l|}{ Place of birth } \\
\hline Denizli province capital & 672 & 30.7 \\
\hline Denizli towns & 1068 & 48.9 \\
\hline Other provinces & 413 & 18.9 \\
\hline Not known & 32 & 1.5 \\
\hline \multicolumn{3}{|l|}{ Gender } \\
\hline Female & 959 & 43.9 \\
\hline Male & 1226 & 56.1 \\
\hline \multicolumn{3}{|l|}{ Educational status } \\
\hline No formal education & 513 & 23.5 \\
\hline Primary school & 1325 & 60.6 \\
\hline High school and equivalent & 142 & 6.5 \\
\hline University & 77 & 3.5 \\
\hline Unknown & 128 & 5.9 \\
\hline \multicolumn{3}{|l|}{ Occupation } \\
\hline Unemployed & 862 & 39.5 \\
\hline Agricultural, animal breeding, forestry workers & 503 & 23.0 \\
\hline Scientific technician, independently employed & 220 & 10.1 \\
\hline Workers in manufacturing (other than agricultural) & 75 & 3.4 \\
\hline Service assistant type workers at worksites & 63 & 2.9 \\
\hline Administrative personnel & 57 & 2.6 \\
\hline Salespeople & 35 & 1.5 \\
\hline Heavy laborers & 23 & 1.1 \\
\hline Retired & 255 & 11.7 \\
\hline Unknown & 92 & 4.2 \\
\hline \multicolumn{3}{|l|}{ Family history of cancer } \\
\hline None & 1613 & 73.8 \\
\hline First degree & 60 & 2.2 \\
\hline Second degree & 198 & 9.1 \\
\hline Both & 13 & 0.6 \\
\hline Unknown & 301 & 13.8 \\
\hline \multicolumn{3}{|l|}{ Cigarette smoking status } \\
\hline Never smoked & 1141 & 52.2 \\
\hline Quit & 513 & 23.5 \\
\hline Still smoking & 473 & 21.6 \\
\hline Unknown & 60 & 2.7 \\
\hline Total & 2185 & 100.0 \\
\hline
\end{tabular}

We found that $45.1 \%$ of the cancer cases had smoked cigarettes at some time in their lives and that $21.6 \%$ of the cancer cases continued to smoke in spite of being diagnosed with cancer. In women who did not smoke cigarettes, the most common cancer was breast (31.3\%), skin $(11.4 \%)$, colorectal $(7.7 \%)$, ovarian $(5.2 \%)$, and uterine cancers $(4.6 \%)$; in women who were cigarette smokers the top five were, respectively, breast (34.4\%), lung (8.2\%), colorectal $(8.2 \%)$, lymphatic (6.6\%) and bone marrow, brain, renal, and bone cancers (all at $4.9 \%)$.

In men who did not smoke cigarettes, the most common cancers were skin $(16.6 \%)$, colorectal $(13.6 \%)$, prostate $(12.5 \%)$, bone marrow $(8.3 \%)$, and lymphatic $(6.0 \%)$ cancers. In the cigarette smokers these were, respectively, lung $(29.7 \%)$, bladder $(14.8 \%)$, colorectal $(13.6 \%)$, prostate $(8.7 \%)$, and skin $(7.9 \%)$ cancers. Cigarette smoking was found to have a statistically significant effect $(\mathrm{P}<0.001)$ on the type of cancer according to gender for all age groups. The risk of developing lung cancer in the general population for non-smokers was 
found to be $12.3 \%$, but it was $37.9 \%$ for cigarette smokers. In the examination of the relationship between cigarette smoking and lung cancer according to gender, it was determined that $4.2 \%$ of the male non-smokers had lung cancer compared to $41.8 \%$ of the men who continued to smoke. Cigarette smoking increased lung cancer by approximately 10 -fold, which was found to be statistically significant $(\mathrm{P}<0.001)$. Because the percentage of women who smoked cigarettes was lower, the effect of cigarette smoking on lung cancer was not observed. We determined that $3.4 \%$ of the non-smokers had lung and $3.0 \%$ had bladder cancer, and that there is a 4-fold increase in urinary cancers $(14.0 \%)$ among the cigarette smokers $(\mathrm{P}<0.001)$.

One-fifth of the cases were diagnosed in the distant metastatic stage $(21.8 \%)$ and $27.9 \%$ in the regional dissemination stage. The methods of diagnosis most frequently used were pathology, cytology, hematology, clinical, and surgical, and the most frequently used methods of treatment were surgical $(57.0 \%)$ and chemotherapy $(50.4 \%)$.

In the distribution of cancer in men and women according to age group and organ system, almost half (43.4\%) of all cancers in women were reproductive cancers and appeared after 30 years of age. This is followed by gastrointestinal (19.6\%) and skin (10.9\%) cancers. The most frequently cancers in men were respiratory cancer $(30.5 \%)$, gastrointestinal $(19.2 \%)$ and urinary $(14.9 \%)$ cancers. There was a clear increase in cancer cases in men after 45 years of age. The cancers in men and women were examined according to age group and organ system. According to this, it is noteworthy that there was an increase in reproductive cancers, which make up $43.4 \%$ of all cancers in women, after the age of 30 years. The next most common cancers in women were $19.6 \%$ for gastrointestinal cancers and $10.9 \%$ for skin cancers. In men, it is interesting that the most common was respiratory cancers $(30.5 \%)$ followed by gastrointestinal cancers at $19.2 \%$ and urinary cancers at $14.9 \%$. A clear increase in cancer cases was shown in men over 45 years $(\mathrm{P}<0.001)$ (Table 3$)$.

Table 3. Distribution of cancer in women by age group and organ system.

\begin{tabular}{|c|c|c|c|c|c|c|c|c|c|c|c|c|c|c|c|c|c|c|c|}
\hline \multirow[t]{2}{*}{ Cancer type } & \multicolumn{17}{|c|}{ Age groups (years) } & \multirow[t]{2}{*}{ Total } & \multirow[t]{2}{*}{$\% *$} \\
\hline & $0-5$ & $6-10$ & $11-15$ & $16-20$ & $21-25$ & $26-30$ & $31-35$ & $36-40$ & $41-45$ & $46-50$ & $51-55$ & $56-60$ & $61-65$ & $66-70$ & $71-75$ & $76-80$ & $81-101$ & & \\
\hline \multicolumn{20}{|l|}{ Female } \\
\hline Respiratory & & & & & 1 & & 1 & 2 & 3 & 4 & 1 & 4 & 7 & 5 & 8 & 1 & 1 & 38 & 4.1 \\
\hline Gastrointestinal & & 1 & & & 4 & 4 & 4 & 8 & 14 & 21 & 12 & 18 & 21 & 32 & 27 & 13 & 3 & 182 & 19.6 \\
\hline Endocrine & 1 & & & & & 3 & 4 & 2 & 4 & 3 & 4 & & 1 & 1 & 1 & 3 & & 27 & 2.9 \\
\hline Lymph & 1 & 1 & & & & 1 & 5 & & 5 & 1 & 3 & 8 & 7 & 7 & 5 & 4 & 2 & 50 & 5.4 \\
\hline Blood & 2 & 1 & 4 & 1 & 4 & 1 & 4 & 3 & 3 & 3 & 3 & 2 & 4 & 4 & 3 & 2 & 4 & 48 & 5.2 \\
\hline Skin & & & & 2 & & 1 & 1 & & 4 & 11 & 6 & 5 & 20 & 14 & 13 & 12 & 12 & 101 & 10.9 \\
\hline Skeletal & & & 1 & 2 & 1 & & 1 & 2 & 1 & 1 & 1 & & 1 & & 2 & & & 13 & 1.4 \\
\hline Reproductive & & 1 & & & 4 & 5 & 18 & 45 & 63 & 75 & 44 & 39 & 31 & 34 & 32 & 10 & 2 & 403 & 43.4 \\
\hline Nervous & 1 & & 1 & & & & & 2 & 1 & 4 & 7 & 2 & 2 & 4 & 1 & 1 & 1 & 27 & 2.9 \\
\hline Urinary & 1 & 1 & & & & 2 & & 3 & 2 & 1 & 5 & & 6 & 6 & 10 & 1 & 1 & 39 & 4.2 \\
\hline Total & 6 & 5 & 6 & 5 & 14 & 17 & 38 & 67 & 100 & 124 & 86 & 78 & 100 & 107 & 102 & 47 & 26 & 928 & 100.0 \\
\hline \multicolumn{20}{|l|}{ Male } \\
\hline Respiratory & & & 1 & 1 & & & 3 & 10 & 13 & 31 & 38 & 54 & 54 & 79 & 55 & 19 & 3 & 361 & 30.5 \\
\hline Gastrointestinal & 1 & & & & 1 & 2 & 5 & 13 & 12 & 20 & 15 & 23 & 36 & 36 & 39 & 18 & 7 & 228 & 19.2 \\
\hline Endocrine & 1 & & & & 1 & & & & 1 & 4 & & & 1 & 1 & & & & 9 & 0.8 \\
\hline Lymph & 1 & & 1 & 2 & & & 2 & 1 & 6 & 4 & 10 & 3 & 7 & 5 & 5 & 5 & 1 & 53 & 4.5 \\
\hline Blood & 1 & 3 & & 3 & 1 & 5 & 1 & 4 & 6 & 4 & 2 & 5 & 7 & 5 & 8 & 6 & 2 & 63 & 5.3 \\
\hline Skin & & 1 & & 1 & & 2 & 3 & 3 & 2 & 7 & 6 & 9 & 26 & 20 & 19 & 12 & 6 & 117 & 9.9 \\
\hline Skeletal & & 1 & & & & 1 & & & 1 & & 2 & 1 & & 1 & & 1 & & 8 & 0.7 \\
\hline Reproductive & 4 & & 1 & & 4 & 10 & 4 & 3 & 3 & 1 & 5 & 17 & 18 & 24 & 28 & 17 & 12 & 151 & 12.7 \\
\hline Nervous & & & & & & 2 & & 3 & 1 & 4 & & 3 & & 3 & 2 & & & 18 & 1.5 \\
\hline Urinary & 1 & & & & 1 & 1 & 3 & 2 & 5 & 17 & 14 & 19 & 33 & 32 & 24 & 20 & 5 & 177 & 14.9 \\
\hline Total & 9 & 5 & 3 & 7 & 8 & 23 & 21 & 39 & 50 & 92 & 92 & 134 & 182 & 206 & 180 & 98 & 36 & 1185 & 100.0 \\
\hline
\end{tabular}

$* \mathrm{P}<0.00$ 
After evaluating the 10 most common types of cancer in men, according to their age group, we determined that: in men under 40 years of age the top three types of cancer were testis-penis tumors $(21.0 \%)$, bone marrow cancers $(14.3 \%)$, and lung cancers $(11.4 \%)$; in the $40-54$-year- old group, lung $(25.2 \%)$, bladder $(9.9 \%)$ and lymphatic $(9.0 \%)$ cancers; in the 55-64-year-old group, lung $(27.5 \%)$, bladder $(12.5 \%)$ and prostate $(11.2 \%)$ cancers, and in the 65 years and over group, lung $(24.1 \%)$, bladder (14.4\%) and prostate (14.2\%) cancers (Table 4). The increase in bladder cancer after 40 years of age and of prostate and skin cancer after 55 years of age is noteworthy. The differences in the cancer distribution in the age groups were statistically significant $(\mathrm{P}<0.001)$. Although the most common type of cancer for women was breast cancer until age 65 years, breast cancer was $38 \%$ of the cancers for women under 40 years, $45.5 \%$ for women $40-54$ years, and the most common cancer for women over 65 years was skin cancer at 17.0\% (Table 5). The differences in percentages of cancer according to age group in women were found to be statistically significant $(\mathrm{P}<0.05)$.

\begin{tabular}{|c|c|c|}
\hline Age group & $\mathrm{N}$ & $\%$ \\
\hline \multicolumn{3}{|c|}{ Under 40 years $(\mathrm{N}=105)$} \\
\hline Testis-penis tumor & 22 & 21.0 \\
\hline Bone marrow & 15 & 14.3 \\
\hline Lung & 12 & 11.4 \\
\hline Skin & 9 & 8.6 \\
\hline Pancreas & 6 & 5.7 \\
\hline Bladder & 6 & 5.7 \\
\hline Colorectal & 6 & 5.7 \\
\hline Lymphatic system & 6 & 5.7 \\
\hline Brain & 4 & 3.8 \\
\hline Prostate & 3 & 2.9 \\
\hline Other & 16 & 15.5 \\
\hline \multicolumn{3}{|c|}{$40-54$ years old $(N=222)$} \\
\hline Lung & 56 & 25.2 \\
\hline Bladder & 22 & 9.9 \\
\hline Lymphatic system & 20 & 9.0 \\
\hline Colorectal & 19 & 8.6 \\
\hline Skin & 15 & 6.9 \\
\hline Stomach & 11 & 5.0 \\
\hline Renal & 11 & 5.0 \\
\hline Bone marrow & 9 & 4.1 \\
\hline Pancreas & 6 & 2.7 \\
\hline Brain & 6 & 2.7 \\
\hline Other & 47 & 21.1 \\
\hline \multicolumn{3}{|c|}{ 55-64 years old $(\mathrm{N}=295)$} \\
\hline Lung & 81 & 27.5 \\
\hline Bladder & 37 & 12.5 \\
\hline Prostate & 33 & 11.2 \\
\hline Skin & 27 & 9.2 \\
\hline Colorectal & 22 & 7.5 \\
\hline Stomach & 20 & 6.8 \\
\hline Larynx & 14 & 4.7 \\
\hline Bone marrow & 10 & 3.4 \\
\hline Renal & 9 & 3.1 \\
\hline Lymphatic system & 9 & 3.1 \\
\hline Other & 33 & 11.2 \\
\hline \multicolumn{3}{|c|}{65 years and over $(\mathrm{N}=557)$} \\
\hline Lung & 134 & 24.1 \\
\hline Bladder & 80 & 14.4 \\
\hline Prostate & 79 & 14.2 \\
\hline Skin & 64 & 11.5 \\
\hline Colorectal & 45 & 7.0 \\
\hline Stomach & 24 & 4.3 \\
\hline Bone marrow & 18 & 3.2 \\
\hline Lymphatic system & 17 & 3.1 \\
\hline Bronchus & 16 & 2.9 \\
\hline Larynx & 15 & 2.7 \\
\hline Other & 65 & 11.7 \\
\hline
\end{tabular}




\begin{tabular}{|c|c|c|}
\hline Age group & $\mathrm{N}$ & $\%$ \\
\hline \multicolumn{3}{|c|}{ Under 40 years $(\mathrm{N}=142)$} \\
\hline Breast & 54 & 38.0 \\
\hline Bone marrow & 15 & 10.6 \\
\hline Ovarian & 8 & 5.6 \\
\hline Lymphatic system & 8 & 5.6 \\
\hline Colorectal & 6 & 4.2 \\
\hline Renal & 6 & 4.2 \\
\hline Thyroid & 6 & 4.2 \\
\hline Bone & 6 & 4.2 \\
\hline Stomach & 5 & 3.5 \\
\hline Skin & 4 & 2.8 \\
\hline Other & 24 & 16.9 \\
\hline \multicolumn{3}{|c|}{$40-54$ years old $(\mathrm{N}=308)$} \\
\hline Breast & 140 & 45.5 \\
\hline Colorectal & 23 & 7.5 \\
\hline Ovarian & 19 & 6.2 \\
\hline Skin & 19 & 6.2 \\
\hline Uterus & 12 & 3.9 \\
\hline Stomach & 11 & 3.6 \\
\hline Brain & 11 & 3.6 \\
\hline Cervix & 11 & 3.6 \\
\hline Thyroid & 11 & 3.6 \\
\hline Bone marrow & 10 & 3.2 \\
\hline Other & 41 & 13.3 \\
\hline \multicolumn{3}{|c|}{$55-64$ years old $(\mathrm{N}=170)$} \\
\hline Breast & 43 & 25.3 \\
\hline Skin & 23 & 13.5 \\
\hline Lymphatic system & 12 & 7.1 \\
\hline Colorectal & 12 & 7.0 \\
\hline Ovarian & 11 & 6.5 \\
\hline Uterus & 10 & 5.9 \\
\hline Lung & 7 & 4.1 \\
\hline Cervix & 6 & 3.5 \\
\hline Stomach & 6 & 3.5 \\
\hline Brain & 5 & 2.9 \\
\hline Other & 35 & 20.6 \\
\hline \multicolumn{3}{|c|}{65 years and older $(\mathrm{N}=305)$} \\
\hline Skin & 52 & 17.0 \\
\hline Breast & 49 & 16.1 \\
\hline Colorectal & 32 & 10.5 \\
\hline Lymphatic system & 22 & 7.2 \\
\hline Uterus & 17 & 5.6 \\
\hline Bladder & 15 & 4.9 \\
\hline Lung & 15 & 4.9 \\
\hline Gall bladder & 14 & 4.6 \\
\hline Bone marrow & 14 & 4.6 \\
\hline Pancreas & 11 & 3.6 \\
\hline Other & 64 & 21.0 \\
\hline
\end{tabular}

The site of cancer for one-fourth of the cancer cases in men was lung, followed by bladder $(12.6 \%)$, skin $(9.9 \%)$, prostate $(9.6 \%)$, and colon $(8.3 \%)$. One-third of the cancer cases in women were located in the breast $(31.7 \%)$. This was followed by skin $(10.8 \%)$, colon $(8.3 \%)$, lymph $(5.2 \%)$, and ovary $(5.0 \%)$. Lung $(14.9 \%)$, breast $(14.1 \%)$, bladder $(8.0 \%)$, prostate $(5.3 \%)$, and lymphatic $(4.8 \%)$ cancer cases were the most commonly seen. In the evaluation by system, the first three were reproductive $(26.4 \%)$, gastrointestinal $(19.2 \%)$ and respiratory $(18.9 \%)$ system, and it is noteworthy that an increase was seen in gastrointestinal, blood and skin cancers over the years $(\mathrm{P}<0.001)$. When the most common site for cancer by organ was examined for both genders it was seen that in men one-fourth of the cancer cases were lung cancer, followed by bladder (12.6\%), skin $(9.9 \%)$, prostate $(9.6 \%)$, and colon $(8.3 \%)$ cancers. In women, one-third of the cancer 
cases were breast cancer (31.7\%), followed by skin (10.8\%), colon (8.3\%), lymph (5.2\%), and ovarian $(5.0 \%)$ cancers (Figure 1).

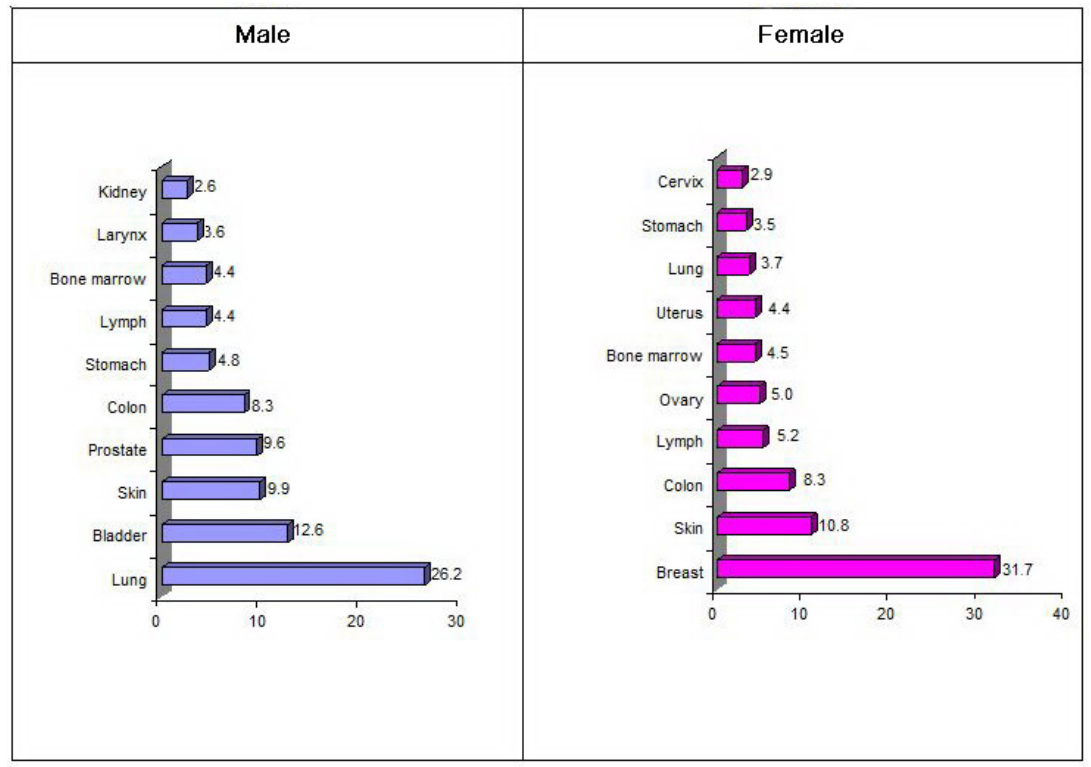

Figure 1. Percentages of most common cancer cases in Denizli until the end of 2004 according to gender.

In the distribution of cancer by year and gender, there were 229 cancer cases in 2000 , which increased approximately 3 -fold to 601 in 2004 . There was an increase in numbers for both genders by year, but it is noteworthy that there was a greater increase in women (Figure 2).

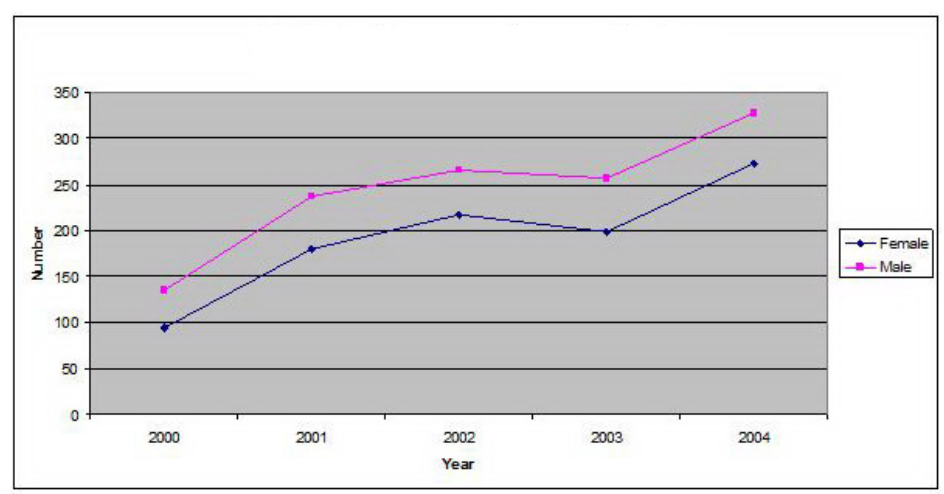

Figure 2. Distribution of cancer by year and gender.

\section{DISCUSSION}

In this study, $43.9 \%$ of the cases of cancer were female and $56.1 \%$ were male. The finding of higher rates of cancer in men is consistent with another study conducted in Turkey (Süzek et 
al., 2004). The mean age of the men was $60.67 \pm 14.9$ years and of the women it was $55.09 \pm 15.8$ years, which are higher than in some other countries. In Pakistan, it has been reported that the mean age for all cancer patients is 45.2 years (Bhurgri et al., 2005). Because cancer is diagnosed in later stages in our country, the mean age may appear to be higher. In our research, approximately onefifth of the cases were in the distant metastases stage.

In our study, approximately half of the cancer cases came from the towns in the province, with more than half having only primary school education, and those working in agriculture, animal breeding and forestry had higher rates of cancer than in other occupations. In addition, heavy job laborers were found to be a high risk group for respiratory, gastrointestinal and skin cancers. In our study group, taking into consideration that those working in rural areas and in the agricultural sector had lower levels of education and that the percentage of cigarette smokers was high in these groups, these factors may trigger cancers. In previous research, cancer prevalence has been reported to show variation related to occupation, lifestyle, environmental conditions, and cancer prevention programs (Hemminki and Li, 2003). In addition, although the organs involved with cancer and their percentages are not the same in different countries, there are fewer deaths from cancer in developed countries. This points out the importance of improving the educational level and early diagnosis in developing countries (Lorenzo and Hemminki, 2005).

Although the majority of cancer patients (73.8\%) did not have a family history of cancer, in those who did there was an increase in reproductive, respiratory, gastrointestinal, and skin cancers.

In addition, the rate of cancer has been reported to have increased over the years in some studies due to many factors (http://www.turkkanser.org.tr/newsfiles/61dunya_kanser_istatistikleri.pdf). In our study, $45.1 \%$ of the cancer cases had smoked cigarettes at some time in their lives and $21.6 \%$ continued to smoke, in spite of being diagnosed with cancer. We found that there was a 10 -fold increase in lung cancer and 4-fold increase in urinary cancer for the cigarette smokers. The correlation between cigarette smoking and cancer in our study is in agreement with literature findings. Cigarettes have been determined to be the most important risk factor for cancer (Döşemeci et al., 1997). The smoking-related cancer sites were also as observed in other countries (Levi et al., 1996; Howe et al., 2001).

There was a steady increase in the numbers of all cancer cases over the years. The part that the improvement of the cancer registration system in Denizli has had on this increase cannot be ignored. However, it is a fact that there are daily important increases in cancer cases in both Turkey (Fidaner et al., 2001; Turkish Republic Health Ministry Fighting Cancer Department, 2002; Bitiren et al., 2003; Kılıç et al., 2004; Genç and Avunduk, 2005) and in the rest of the world (Razum et al., 2000; Bray et al., 2002; Eaton, 2003; Parkin et al., 2005; Jemal et al., 2007). The increase in incidence rates has been evidenced also in France; rates increased from the 1970s to 1980, and then in 1990s they leveled off in males but continued to increase in females (Menegoz et al., 1997). Also, in Switzerland from 1974 to 1993, there was an increase in the overall incidence rates, whereas mortality remained approximately stable (Levi et al., 1996). Cancer incidence trends in central Italy from mid-1980s to late 1990s showed some differences between sexes (Crocetti et al., 2002).

In this study, the most common site for cancer by organ was examined for both sexes. It was seen that in men one-fourth of the cancer cases were lung cancer, followed by bladder, skin, prostate, and colon cancers. In women one-third of the cancer cases were breast cancer followed by skin, colon, lymph, and ovarian cancers. When the organs were examined as sites for cancer, it was seen that our findings were similar to those reported in the international literature for the first five sites http://www.turkkanser.org.tr/newsfiles/60turkiye_kanser_istatistikleri-2.pdf). In central Italy, for females, there were increasing rates in some of the most frequent cancer sites (e.g., breast, 
skin, colon, and lung) (Crocetti et al., 2002). In a study conducted in Turkey by Kılıç et al. (2004), however, the first five cancers in women were reported to be breast, colorectal, stomach and lung cancers, and non-Hodgkins lymphoma. In men these were, respectively, lung, colorectal and stomach cancers, testis tumors, and non-Hodgkins lymphoma. In the world, Europe and in developed countries, lung cancer is the first cancer in men (Kıliç et al., 2004). In other studies on the European continent, it has been reported that the rate of lung cancer has decreased in recent years (Crocetti et al., 2002; La Vecchia, 2003). In Turkey, lung cancer remains in first place, particularly for men (Fidaner et al., 2001; Kılıç et al., 2004). A previous study showed the high individual and societal cost of lung cancer with poor prognosis and detrimental effects on the economy of Turkey as a developing country (Çakır and Karlıkaya, 2007). Colorectal cancers were reported to be the second most common in Europe in 1995 (Bray et al., 2003), but they were first in a Portuguese study (Pinheiro et al., 2003). In a study conducted in Israel, an increase in colorectal cancer for both genders was reported (Rozen et al., 2007). In our study, breast cancer, which was the first most common for women, was also in first place at $24.1 \%$ in the 1999 report from our country (Turkish Republic Health Ministry Fighting Cancer Department, 2002). In a study by Kılıç et al. (2004), it was reported to be in first place at 52.5\%. In European countries as well, they comprised $26.5 \%$ of new cases in 2000 and were responsible for $17.5 \%$ of cancer-related deaths (Tyczynski et al., 2002). Breast cancer has also been found to be in first place in studies conducted in Portugal (25.6\%) and India (22.7\%) (Sen et al., 2002; Pinheiro et al., 2003).

In conclusion, our study showed that a) the most frequently seen cancers in Denizli between 2000-2004 involved the reproductive, gastrointestinal and respiratory systems, b) there was an increase in gastrointestinal and skin cancers over the years, and c) one-fifth of the cancer cases were diagnosed in the distant metastases stage. It is particularly important for early diagnostic methods to be utilized in intestinal cancer, which showed an increase, and for information to be provided about regular dietary habits and physical activity to protect against cancer. In addition, it is important that population-stratified cancer recording systems be established and cancer prevention policies be developed and maintained. When screening programs are developed, the differences in cancer types according to age and gender demographics need to be kept in mind. Because of the high cost of treatment, loss of workforce and the high probability of it resulting in death, it is extremely important for cancer to be prevented or diagnosed early. In every society, the investigation of cancer incidence and etiology helps in the early diagnosis and prevention of cancer. In addition, it will also have a part in treatment methods and achieving successful outcomes from treatment.

\section{REFERENCES}

Bhurgri Y, Bhurgri A, Pervez S, Bhurgri M, et al. (2005). Cancer profile of Hyderabad, Pakistan 1998-2002. Asian Pac. J. Cancer Prev. 6: 474-480.

Bitiren M, Özardali I, Baba F, Nazligül Y, et al. (2003). Sanliurfa Ili’nde kanser kayitlarinin degerlendirilmesi (19952002). Tr. Ekopatol. Derg. 9: 11-16. Available at [http://vantipdergisi.yyu.edu.tr/97-4/2.\%20Klinik.pdf].

Bray F, Sankila R, Ferlay J and Parkin DM (2002). Estimates of cancer incidence and mortality in Europe in 1995. Eur. J. Cancer 38: 99-166.

Bray F, Guerra YM and Parkin DM (2003). The comprehensive cancer monitoring programme in Europe. Eur. J. Public Health 13: 61-66.

Çakir EE and Karlikaya C (2007). The cost of lung cancer in Turkey. Tuberk. Toraks. 55: 51-58.

Crocetti E, Paci E, Miccinesi G, Costantini AS, et al. (2002). Time trends in cancer incidence and mortality in central Italy. Eur. J. Cancer Prev. 11: 387-395.

Döşemeci M, Gokmen I, Unsal M, Hayes RB, et al. (1997). Tobacco, alcohol use, and risks of laryngeal and lung cancer 
by subsite and histologic type in Turkey. Cancer Causes Control 8: 729-737.

Eaton L (2003). World cancer rates set to double by 2020. BMJ 326: 728.

Fidaner C, Eser SY and Parkin DM (2001). Incidence in Izmir in 1993-1994: first results from Izmir Cancer Registry. Eur. J. Cancer 37: 83-92.

Genç M and Avunduk MC (2005). Analysis of cancer cases in Konya. Int. J. Hematol. Oncol. 15: 189-194.

Hemminki K and Li X (2003). Level of education and the risk of cancer in Sweden. Cancer Epidemiol. Biomarkers Prev. 12: 796-802.

Howe HL, Wingo PA, Thun MJ, Ries LA, et al. (2001). Annual report to the nation on the status of cancer (1973 through 1998), featuring cancers with recent increasing trends. J. Natl. Cancer Inst. 93: 824-842.

Jemal A, Tiwari RC, Murray T, Ghafoor A, et al. (2004). Cancer statistics, 2004. CA Cancer J. Clin. 54: 8-29.

Jemal A, Siegel R, Ward E, Murray T, et al. (2007). Cancer statistics, 2007. CA Cancer J. Clin. 57: 43-66.

Kiliç S, Kömürcü S, Rzayev M, Özet A, et al. (2004). Some sociodemographic characteristics and diagnoses of patients, followed at Gülhane Military Medical Academy, Department of Medical Oncology. Gülhane Tip Derg. (Gulhane Med. J.) 46: 115-124.

La Vecchia C, Franceschi S and Levi F (2003). Epidemiological research on cancer with a focus on Europe. Eur. J. Cancer Prev. 12: 5-14.

Levi F, Te VC, Randimbison L and La Vecchia C (1996). Trends in cancer incidence and mortality in Vaud, Switzerland, 1974-1993. Ann. Oncol. 7: 497-504.

Lorenzo BJ and Hemminki K (2005). Familial lung cancer and aggregation of smoking habits: a simulation of the effect of shared environmental factors on the familial risk of cancer. Cancer Epidemiol. Biomarkers Prev. 14: 1738-1740.

Menegoz F, Black RJ, Arveux P, Magne V, et al. (1997). Cancer incidence and mortality in France in 1975-95. Eur. J. Cancer Prev. 6: 442-466.

Parkin DM (2001). Global cancer statistics in the year 2000. Lancet Oncol. 2: 533-543.

Parkin DM, Pisani P and Ferlay J (1999). Estimates of the worldwide incidence of 25 major cancers in 1990. Int. J. Cancer 80: 827-841.

Parkin DM, Bray F, Ferlay J and Pisani P (2005). Global cancer statistics, 2002. CA Cancer J. Clin. 55: 74-108.

Pinheiro PS, Tyczynski JE, Bray F, Amado J, et al. (2003). Cancer incidence and mortality in Portugal. Eur. J. Cancer 39: $2507-2520$.

Razum O, Zeeb H, Beck K, Becher H, et al. (2000). Combining a name algorithm with a capture-recapture method to retrieve cases of Turkish descent from a German population-based cancer registry. Eur. J. Cancer 36: 2380-2384.

Rozen P, Liphshitz I and Barchana M (2007). Changing sites of colorectal cancer in the Israeli Jewish ethnic populations and its clinical implications. Eur. J. Cancer Prev. 16: 1-9.

Sen U, Sankaranarayanan R, Mandal S, Ramanakumar AV, et al. (2002). Cancer patterns in eastern India: the first report of the Kolkata cancer registry. Int. J. Cancer 100: 86-91.

Sørensen HT, Mellemkjaer L, Skriver MV, Johnsen SP, et al. (2005). Fever of unknown origin and cancer: a populationbased study. Lancet Oncol. 6: 851-855.

Süzek H, Karakus A and Güler Y (2004). 1998-2002 Yillari Mugla Ili Kanser Kayýtlarýnýn Degerlendirilmesi. Insan Bilimleri Dergisi ISSN:1303-5134, Available at [www.insanbilimleri.com]: 1-7.

Turkish Ministry of Health (1997). Cancer Registry Report of Turkey 1993-1994. Ministry of Health, Department of Cancer Control, Ankara.

Turkish Republic Health Ministry Fighting Cancer Department, Ministry Publication (2002). Fighting Cancer Policy and Cancer Data, 1995-1999. No: 618, Ankara, 145.

Turkish Republic Ministry of State Statistics Institute Publications (2002). 1999 Death Statistics in Towns and Province Capitals, Ankara, 59.

Tyczynski JE, Bray F and Maxwell-Parkin D (2002). Breast Cancer in Europe. ENCR (European Network of Cancer Registries) Cancer Fact Sheets. Vol. 2.

WHO (World Health Organization) (1992). Manual for International Classification of Diseases and Health Related Problems, 10th revision. World Health Organization, Geneva.

WHO (World Health Organization) (2003). Consultation strategies to improve and strengthen cancer control programmes in Europe. In: Report of the WHO Meeting 25-28 November. World Health Organization, Geneva. 